\title{
Plasticity and stability of hybrid aspen clones in 14 field trials over Sweden, Finland and north-west Russia
}

\author{
Aleksey Fedorkov ${ }^{1} \bowtie$, Lars-Göran Stener ${ }^{2}$, Pertti Pulkkinen $^{3}$ \\ ${ }^{1}$ Institute of Biology, Komi Science Centre, Russian Academy of Sciences, Kommunisticheskaya 28, \\ Syktyvkar 167982, Russia, e-mail: fedorkov@ib.komisc.ru \\ ${ }^{2}$ The Forestry Research Institute of Sweden (Skogforsk), Ekebo 2250, SI-26890 Svalöv, Sweden, \\ e-mail: Lars-Goran.Stener@skogforsk.se \\ ${ }^{3}$ Natural Resources Institute Finland (Luke), Latokartanonkaari 9, FI-00790 Helsinki, Finland, \\ e-mail: pertti.pulkkinen@luke.fi
}

\begin{abstract}
The study aimed at estimating the genotype $\times$ environment $(\mathrm{G} \times \mathrm{E})$ interaction, stability and plasticity parameters for height growth and survival of hybrid aspen (Populus tremula L. $\times$ Populus tremuloides Michx.) clones. A set of 17 hybrid aspen clones were studied at age four in 11 field trials (series 1) and a set of 12 clones were studied at age 12 in three field trials (series 2) in Sweden, Finland and north-west Russia. There was an intermediate and significant correlation between height ranks at four and 12 years, showing modest $\mathrm{G} \times \mathrm{E}$ interaction for tree height. The corresponding correlation for survival was weak and insignificant, indicating a stronger $\mathrm{G} \times \mathrm{E}$ interaction than for height. The stability parameter $(S)$ for height showed large differences among clones. The plasticity index $(P I)$ values for height ranged from 0.6 to 0.8 among clones, demonstrating high levels of phenotypic plasticity.
\end{abstract}

\section{KEY WORDS}

genotype $\times$ environment interaction, plasticity, Populus tremula, Populus tremuloides, stability, survival, tree height

\section{INTRODUCTION}

Fast-growing hybrid aspen (Populus tremula L. $\times$ Populus tremuloides Michx.) are currently of large interest in the Nordic and Baltic countries (Beuker 2000; Rytter and Stener 2005; Tullus et al. 2007; Žiauka et al. 2013; Jansons et al. 2014). Hybrid aspen is considered to be a promising alternative in the boreal and hemi boreal zones, since it seems to combine fast growth and wood quality with high frost hardiness (Heräjärvi and Junkkonen 2006; Tullus et al. 2012).
Testing of promising candidate clones within the expected deployment area is an essential phase in practical breeding, prior selection of clones for commercial use. Thus, several field tests including the same clones are normally established to get information about the climatic adaptation at different sites. Such a design makes it possible to test genotype by environment $(\mathrm{G} \times \mathrm{E})$ interactions.

According to a review published recently by $\mathrm{Li}$ et al. (2017), a high level of $G \times E$ interaction is usually found for growth traits of different tree species. For hy- 
brid aspen, significant $\mathrm{G} \times \mathrm{E}$ interaction for growth has been observed for 25 clones on four sites in Finland ( $\mathrm{Yu}$ and Pulkkinen 2003). Similarly, a strong $\mathrm{G} \times \mathrm{E}$ interaction for height growth was found in a study of two tests with poplar and aspen hybrids in Lithuania (Pliūra et al. 2014). On the other hand, only a weak $G \times E$ interaction was derived from a series of clonal field trials with hybrid aspen and poplars in Sweden (Stener and Karlsson 2004; Stener and Westin 2017). In addition, no significant interaction was found by Nielsen et al. (2014) in two poplar clonal tests in Denmark.

A $G \times E$ interaction means that genotypes are ranked differently in different environments, that is, clones may perform well at one site but poorly at another site. Moreover, different traits may exhibit different patterns of $\mathrm{G} \times \mathrm{E}$ interaction ( $\mathrm{Li}$ et al. 2017). This complicates the selection of well-performing clones for commercial use. High-yielding genotypes that perform well in a wide range of environments, that is, with high level of stability and plasticity, are to be preferred (Gullberg and Vegerfors 1987; Karlsson et al. 2001).

The climate, especially spring or autumn frost weather condition could be a main driver for $\mathrm{G} \times \mathrm{E}$ interaction as, for instance, shown for height growth of Norway spruce in southern and central Sweden (Chen et al. 2017). For Scots pine in northern Sweden, strong pattern of $\mathrm{G} \times \mathrm{E}$ for both tree vitality and height was detected due to differences in temperature sums among trials (Calleja-Rodrigues et al. 2019). The climate change will create new growing conditions, where higher temperatures are supposed to increase growth (Jylhä et al. 2009). However, there may be a risk that growth will start too early or end too late, increasing the risk of frost damage and thus, making clones with high plasticity and/or high stability more favourable.

The objectives of this work were to 1) study genotype $\times$ environment interactions for hybrid aspen clones and 2) estimate stability and plasticity parameters for height growth and survival.

\section{Material AND MEthods}

\section{Field trials and material}

The study is based on data from two series of clonal field trials with hybrid aspen. Series 1 consists of 10 trials planted in 2010-2011 from latitude $56^{\circ}$ to $64^{\circ}$ in Sweden (Swe 1-Swe 10; Stener and Westin 2017) and one trial at latitude $61^{\circ}$ in north-west Russia (Ru 1). Series 2 consists of three trials planted in 2002 in southern Finland (Fi 1-Fi 3; Tab. 1).

Table 1. Description of the hybrid aspen field trials over Sweden (Swe), Finland (Fi) and north-west Russia (Ru) included in the study

\begin{tabular}{|c|c|c|c|c|c|c|c|}
\hline Trial & Name & Type of land & Planted year & Lat $\left[\mathrm{N}^{\circ}\right]$ & Long $\left[\mathrm{E}^{\circ}\right]$ & Alt $[\mathrm{m}]$ & Temp. [sum, d.d] \\
\hline Swe 1 & Sturup & agricultural & 2010 & $56^{\circ} 34^{\prime}$ & $13^{\circ} 23^{\prime}$ & 120 & 1527 \\
\hline Swe 2 & Malteröd & forest & 2010 & $56^{\circ} 07^{\prime}$ & $13^{\circ} 37^{\prime}$ & 114 & 1501 \\
\hline Swe 3 & Toftaholm & forest & 2010 & $56^{\circ} 59^{\prime}$ & $14^{\circ} 03^{\prime}$ & 162 & 1405 \\
\hline Swe 4 & Remningstorp & agricultural & 2010 & $58^{\circ} 16^{\prime}$ & $13^{\circ} 22^{\prime}$ & 133 & 1359 \\
\hline Swe 5 & Harg & agricultural & 2010 & $60^{\circ} 05^{\prime}$ & $18^{\circ} 15^{\prime}$ & 29 & 1356 \\
\hline Swe 6 & Karön & forest & 2010 & $60^{\circ} 10^{\prime}$ & $18^{\circ} 13^{\prime}$ & 25 & 1347 \\
\hline Swe 7 & Pommac & forest & 2011 & $63^{\circ} 07^{\prime}$ & $17^{\circ} 27^{\prime}$ & 265 & 961 \\
\hline Swe 8 & Ed & agricultural & 2011 & $63^{\circ} 15^{\prime}$ & $17^{\circ} 14^{\prime}$ & 75 & 1124 \\
\hline Swe 9 & Degerbyn & agricultural & 2011 & $64^{\circ} 47^{\prime}$ & $20^{\circ} 49^{\prime}$ & 20 & 1086 \\
\hline Swe 10 & Degerbyn & forest & 2011 & $64^{\circ} 47^{\prime}$ & $20^{\circ} 49^{\prime}$ & 20 & 1086 \\
\hline $\mathrm{Ru} 1$ & Syktyvkar & agricultural & 2010 & $61^{\circ} 39^{\prime}$ & $50^{\circ} 44^{\prime}$ & 157 & 1075 \\
\hline Fi 1 & Sääksjärvi & agricultural & 2002 & $60^{\circ} 36^{\prime}$ & $25^{\circ} 22^{\prime}$ & 70 & 1274 \\
\hline Fi 2 & Sävträsk & agricultural & 2002 & $60^{\circ} 32^{\prime}$ & $26^{\circ} 05^{\prime}$ & 35 & 1322 \\
\hline Fi 3 & Laukonsaari & agricultural & 2002 & $61^{\circ} 49^{\prime}$ & $29^{\circ} 20^{\prime}$ & 85 & 1235 \\
\hline
\end{tabular}


The Swedish trials included in total 109 clones and consisted among others of 29 genotypically selected clones for commercial use in southern Sweden and 23 clones originating from the Finnish breeding programme. In the Russian trial, totally 42 hybrid aspen clones and 8 common aspen clones were tested, and 17 of these were in common with those in the Swedish trials. The Finnish trials included in total 45 hybrid aspen clones out of which 12 were in common with those in trial series 1 . All the clones resulting from crosses between Finnish origin P. tremula as the mothers and Canadian origin $P$. tremuloides as fathers were selected by Natural Resources Institute Finland (Luke) for commercial use in southern Finland. The study was performed on the clones in common (series 1; 17 clones; series 1 and 2; 12 clones).

The Swedish trials were planted in a randomized block and single tree plot design with $6-8$ blocks (mainly 1-2 ramets per clone and block) with a spacing of $3 \times 3 \mathrm{~m}$. To avoid problems from vegetation, the agricultural sites in Sweden were treated with glyphosate herbicide (Roundup) before planting and the forest land sites were prepared by inverted soil scarification. Damage by deer and moose was prevented by fencing. The Russian trial was established in the same manner but without herbicide treatment and fencing. The Finnish trials (series 2) consisted of a randomized complete block design with $5 \times 5$ tree plots for each clone in four replicates, where a spacing of $3 \times 3 \mathrm{~m}$ was used. Herbicides were not used in the Finnish trials but soil scarification was done in patches using an excavator and they were all fenced. All trials were established in spring using dormant, 1-year old container plants that had been produced by the research organizations in each country respectively.

\section{Measurements}

The total height of each individual tree alive was measured in all the trials. This was performed after four growing seasons in series 1, that is, year 2013 in Swe 1-Swe 6 and Ru 1, and 2014 in Swe 7-Swe 10. The trials in series 2 were measured after 12 growing seasons (year 2013). Dead trees were registered as well at all the sites, in order to get a measure of survival.

\section{Statistical analysis}

The statistical analysis was based on clone means of tree height and survival for each trial. Since height and survival deviated from normal distributions according to Shapiro and Wilk-tests (Sabin and Stafford 1990), both traits were analysed by nonparametric tests. The clones were ranked based on mean heights and survival within each trial. To study the stability of individual clones across trials of series 1 , variance of ranks $(S)$ were calculated as proposed by Huehn (1990):

$$
S=\frac{j\left(r_{i j}-\bar{r}_{i}\right)^{2}}{E-1}
$$

where:

$r_{i j}$ - the rank of genotype $i$ in environment (trial) $j$;

$\bar{r}_{i}$ - the mean rank of genotype $i$ overall trials;

$E$ - number of environments.

The plasticity index $(P I)$ of height and survival was for each clone calculated as the difference between maximum and minimum clone mean among the 11 trials in series 1 relative to the maximum mean (Stojnić et al. 2015). The plasticity index values range from zero to one, where zero indicates no plasticity and one is maximum plasticity.

The relationship between clonal ranks for height and survival at the age 4 (series 1) and 12 (series 2) years was tested with the Spearman correlation analysis, as an additional way to describe the $\mathrm{G} \times \mathrm{E}$ interactions. The statistical package Statistica 6.0 was used for all the statistical analyses (SAS/STAT User's Guide 1999).

\section{Results}

Tree height at age four averaged $25 \mathrm{dm}$ over the 11 trials of series 1 and varied from $16 \mathrm{dm}(\mathrm{Ru} 1)$ to $47 \mathrm{dm}$ (Swe 3). Average survival after four years in field was $80 \%$ and varied from $52 \%$ (Swe 8 ) to $96 \%$ (Swe 3). In series 2, tree height after twelve years of growth averaged $96 \mathrm{dm}$, ranging from 90 to $119 \mathrm{dm}$ and average survival was $88 \%$ and varied from 80 to 94\% (Fig. 1).

The stability parameter $(S)$ is illustrated for each clone in series 1 in Figure 2. Low $S$-values indicate 
A

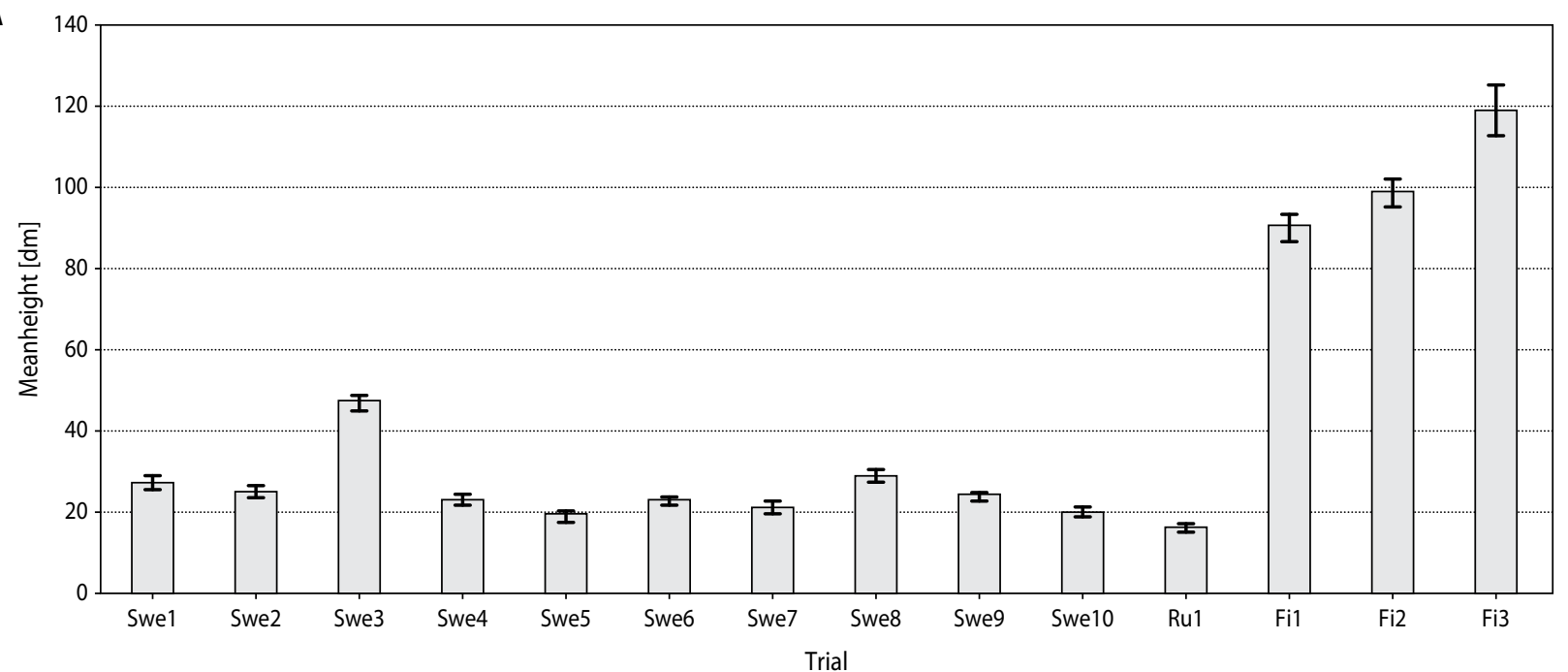

B

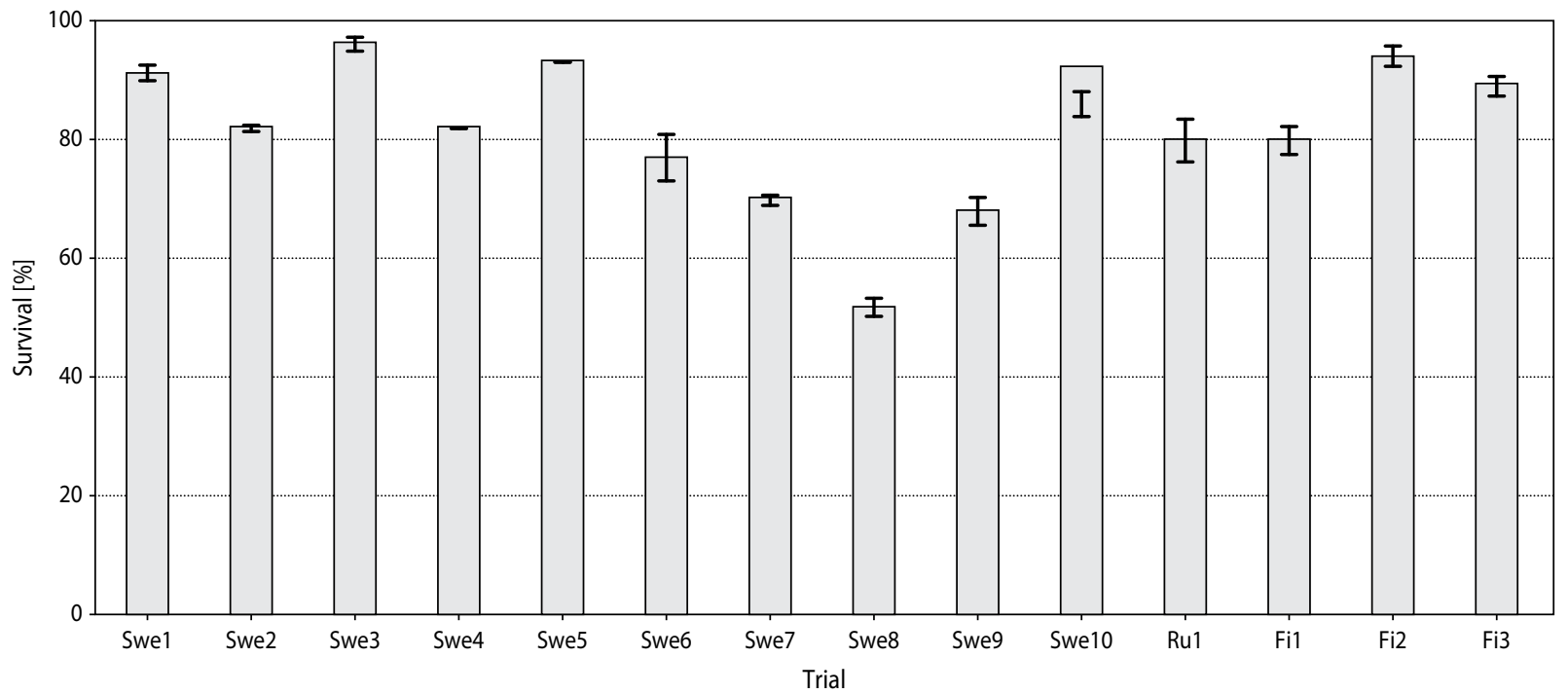

Figure 1. Trial means of height (a) and survival (b) of hybrid aspen clones after four years (Swe1-Swe10, Ru1) and after 12 years (Fil-Fi3) of growth in the field. Vertical bars indicate the standard error.

high stability and high $S$-values indicate low stability. Clonal means of survival and height over all the trials ranged from 75 to $85 \%$ and 18 to $34 \mathrm{dm}$ respectively. In general, the variances of rank estimates were higher and more scattered for survival than for height (Fig. 2). Clone 425 is the only clone, combining high mean growth with high stability. The level of phenotypic plasticity $(P I)$ varied more and was generally lower among the different clones for survival than for height (Fig. 3).
For the 12 clones included in both series, there was an intermediate, positive and significant correlation ( $\mathrm{r}=0.65 ; P<0.05)$ between height ranks, indicating a modest $\mathrm{G} \times \mathrm{E}$ interaction for tree height. The corresponding correlation for survival was weak and insignificant $(\mathrm{r}=0.29 ; P>0.05)$, indicating a stronger $\mathrm{G} \times \mathrm{E}$ interaction than for height. 


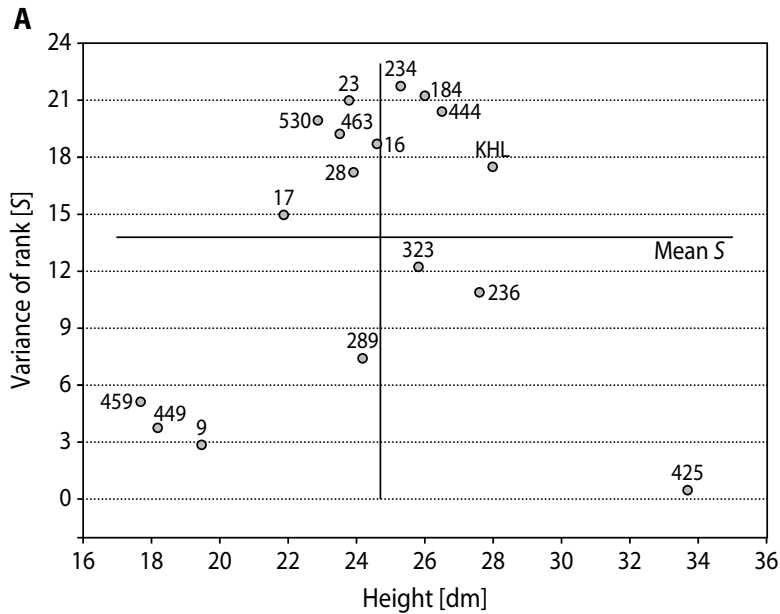

B

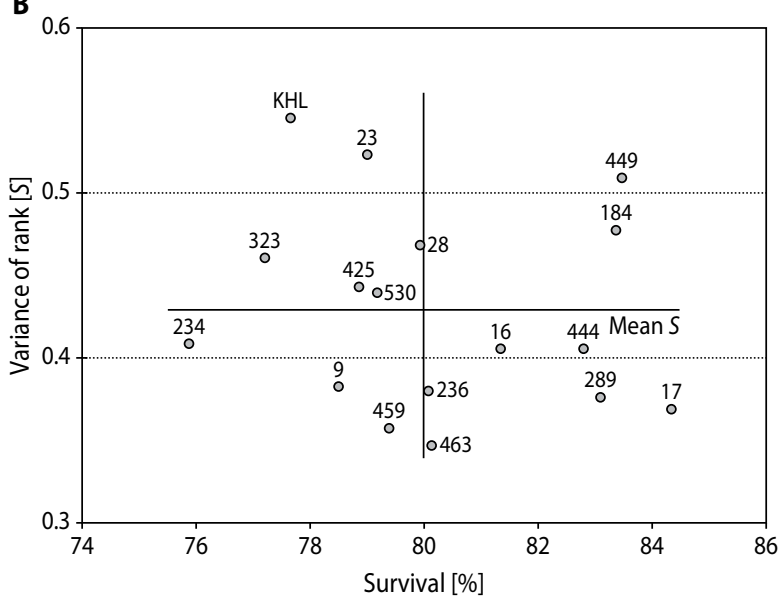

Figure 2. Stability $(S)$, estimated as rank of variance over mean height (a) and mean survival (b) for each hybrid aspen clone in trials of series 1

\section{Discussion AND CONCLUSIONS}

In most of the 14 test sites, the hybrid aspen clones survived well, reflecting a good initial adaptation to the environmental conditions (Fig. 1). Three of the four northern Swedish trials (Swe 7-Swe 9) diverged from this pattern and showed lower survival. This can partly be attributed to vole and hare damages, which were quite frequent in these trials especially at Swe 8 (Ed) (Stener and Westin 2017) but it is also likely due to a transfer effect.

There is no contradiction in the stability $(S)$ and the plasticity $(P I)$ concept. Low values of $S$ means less rank's changing, that is, low level of $\mathrm{G} \times \mathrm{E}$ inter-
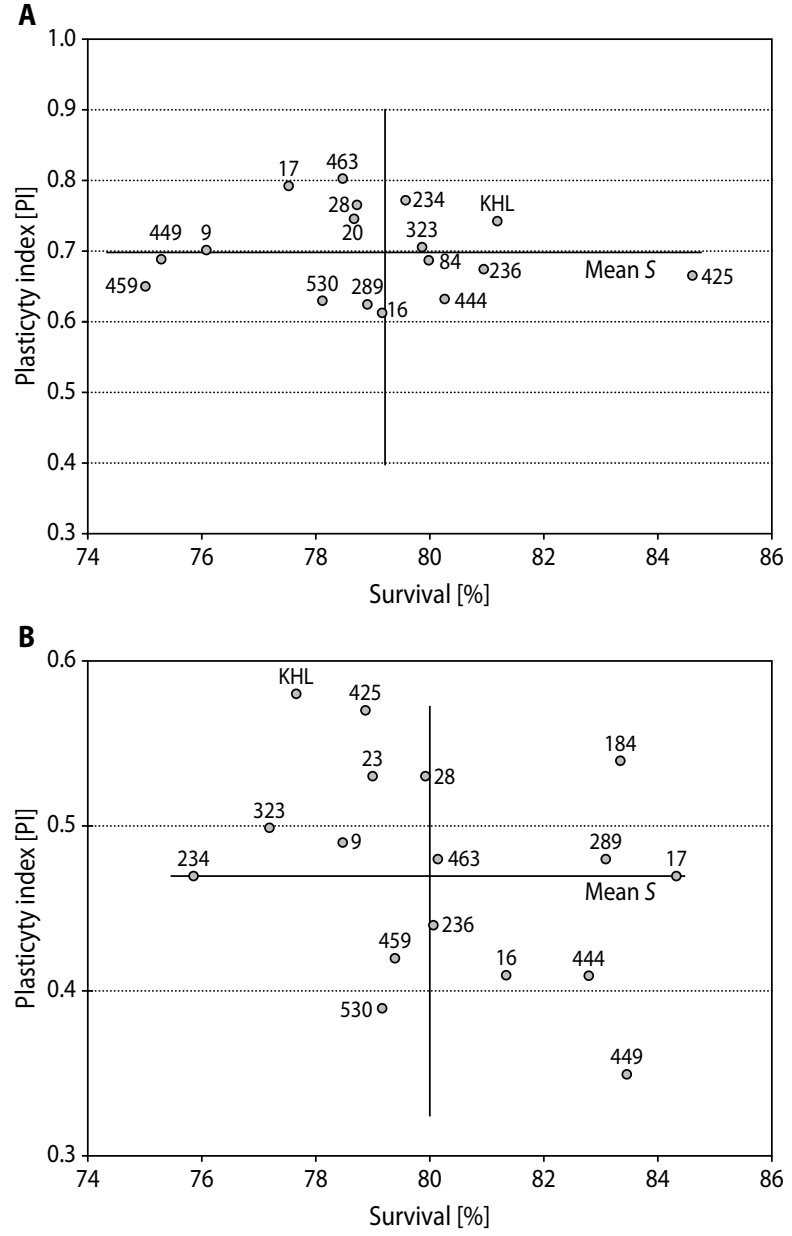

Figure 3. Plasticity index $(P I)$ for height over mean height (a) and mean survival (b) for each hybrid aspen clone in trials of series 1

action and vice versa. High values of $P I$ means that there is extent of variation of clonal means across trials, but the same time the clonal ranking may be more or less stable. According to Karlsson et al. (2001) the ideal forest regeneration material should express a high stability across environments, that is, have the same ranking in all environments. This was not the case in this study, where clear clonal differences were found. The best growing clone (425) showed both high level of stability and plasticity. The worst growing clones (9, 449 and 459) demonstrated high stability and low to moderate values of plasticity compared with other clones (Fig. 2 and 3). The differences in performance of these clones could perhaps 
partly be explained by varying heterosis effects ( $\mathrm{Li}$ et al. 1998). Different parent origin resulting in different growth patterns, that is, length of the growing period, is another possible explanation (Pliūra et al. 2014; Stener and Westin 2017). It may for instance be so that the bad performing clones are growing too long in the autumn, resulting in increased risk of frost damage, unlike clone 425 , which ceases growth in a more optimal way.

High values of stability combined with high growth performance of hybrid aspen clones were reported by Pliūra et al. (2014) in two field tests in Lithuania. Significant clonal variation in height as, observed in this study, is in accordance with the results in the previous studies (Stener and Karlsson 2004, Rytter and Stener 2005), and suggest that there is still a great potential to increase yield further by selecting the most productive clones. According to Yu and Pulkkinen (2003) selection on the overall mean is all that is necessary to assure the largest overall gains.

In general, variances of ranks were higher for survival than for height (Figure 2), indicating that survival is a less stable parameter than height. In addition, less $P I$ values suggest a lower plasticity in comparison to height growth. One reason for the lower $P I$ values is the low variation among clonal means $(<10 \%$; Fig. 3$)$. The mean survival of the best growing clone (425) across all trials was close to the overall mean, having an average stability and high level of plasticity (Fig. 2B and 3B). Modest and weak correlations between ranks of height and survival at age four and twelve can be partly explained by small sample size and different plot size used in the first and the second series of field trials (see Material and Methods).

Taking into account that height growth and survival are usually the primary selection traits in tree breeding in the boreal zone, we conclude that tree height is a more stable and more plastic parameter in comparison to tree survival. In this respect, our results seem to be consistent with data obtained for hybrid aspen by Stener and Karlsson (2004) who found higher broadsense heritabilities for height than survival. The study was based on many sites but with few clones measured at an early age. Still it was considered to get rough but relevant estimations of stability and plasticity of hybrid aspen clones.

\section{ACKNOWLeDGeMENTS}

The authors wish to thank the personnel at the Haapastensyrjä Unit (Luke) and especially forestry engineer Raimo Jaatinen for producing and delivering planting stock to Russia. The establishment of clonal field trial in Syktyvkar was funded by 'Mondi Syktyvkar' pulp and paper mill.

\section{ReferenCes}

Beuker, E. 2000. Aspen breeding in Finland, new challenges. Baltic Forestry, 6 (2), 81-84.

Calleja-Rodriguez, A., Andersson Gull, B., Wu, H.X., Mullin, T.J., Persson, T. 2019. Genotype-by-environment interactions and the dynamic relationship between tree vitality and height in northern Pinus sylvestris. Tree Genetics \& Genomes, 15. DOI: 10.1007/s11295-019-1343-8.

Chen, Z-Q., Karlsson, B., Wu, H.X. 2017. Patterns of additive genotype-by-environment interaction in tree height of Norway spruce in southern and central Sweden. Tree Genetics and Genomes, 13, 25. DOI: 10.1007/s11295-017-1103-6.

Gullberg, U., Vegerfors, B. 1987. Genotype-environment interaction in Swedish material of Pinus sylvestris. Scandinavian Journal of Forest Research, 2, 417-432.

Heräjärvi, H., Junkkonen, R. 2006. Wood density and growth rate of European and hybrid aspen in southern Finland. Baltic Forestry, 12 (1), 2-8.

Huehn, M. 1990. Nonparametric measures of phenotypic stability. Part 1: theory. Euphytica, 47, 189-194.

Jansons, A., Zeps, M., Rieksts-Riekstinš, J., Matisons, R., Krišäns, O. 2014. Height increment of hybrid aspen Populus tremula $\times P$. tremuloides as a function of weather conditions in south-western part of Latvia. Silva Fennica, 48 (5), 13. DOI: $10.14214 /$ sf. 1124

Jylhä, K., Ruosteenoja, K., Räisänen, J., Venäläinen, A., Tuomenvirta, H., Ruokolainen, L., Seitola, T. 2009. Projections of Changes in Climate in Finland for Adaptation Studies. ACCLIM project report 2009 (in Finnish). Ilmatieteenlaitos, Raportteja,:4, 102.

Karlsson, B., Wellendorf, H., Roulund, H., Werner, M. 2001. Genotype $\times$ trial interaction and stability 
across sites in 11 combined provenance and clone experiments with Picea abies in Denmark and Sweden. Canadian Journal of Forest Research, 31, 1826-1835.

Li, B., Howe, G.T., Wu, R. 1998. Developmental factors responsible for heterosis in aspen hybrids (Populus tremuloides $\times$ P. tremula). Tree Physiology, 18, 29-36.

Li, Y., Suontama, M., Burdon, R.D., Dungey, H. 2017. Genotype by environment interactions in forest tree breeding: review of methodology and perspectives on research and application. Tree Genetics and Genomes, 13, 60. DOI: 10.1007/s11295-017-1144-x.

Nielsen, U.B., Madsen, P., Hansen, J.K., Nord-Larsen, T., Nielsen, A.T. 2014. Production potential of 36 poplar clones grown at medium length rotation in Denmark. Biomass and Bioenergy, 64, 99-109. DOI: 10.1016/j.biombioe.2014.03.030

Pliūra, A., Sushockas, V., Sarsekova, D., Gudynaite, V. 2014. Genotypic variation and heritability of growth and adaptive traits, and adaptation of young poplar hybrids at northern margins of natural distribution of Populus nigra in Europe. Biomass and Bioenergy, 70, 513-529. DOI: 10.1016/j.biombioe.2014.09.011

Rytter, L., Stener, L-G. 2005. Productivity and thinning effects in hybrid aspen (Populus tremula L. $\times$ Populus tremuloides Michx.) stands in southern Sweden. Forestry, 78, 285-295. DOI: 10.1093/forestry/cpi026

Sabin, T.E., Stafford, S.G. 1990. Assessing the need for transformation of response variables. Forest Research Laboratory, Oregon State University, Corvallis, Special Publication.
Stener L-G., Karlsson B. 2004. Improvement of Populus tremula $\times P$. tremuloides by phenotypic selection and clonal testing. Forest Genetics, 11, 13-27.

Stener, L.-G., Westin, J. 2017. Early growth and phenology of hybrid aspen and poplar in clonal field tests in Scandinavia. Silva Fennica, 51 (3). DOI: $10.14214 / \mathrm{sf} .5656$

Stojnić, S., Orlović, S., Miljković, D., Galić, Z., Kebert, M., Wuehlisch, G. 2015. Provenance plasticity of European beech leaf traits under differing environmental conditions at two Serbian common garden sites. European Journal of Forest Research, $134,1109-1125$.

SAS Institute Inc. 2004.SAS/STAT 9.1 User's Guide. SAS Publishing, Cary, NC.

Tullus, A., Tullus, H., Vares, A., Kanal, A. 2007. Early growth of hybrid aspen (Populus $\times$ wettsteinii Hämet-Ahti) plantations on former agricultural lands in Estonia. Forest Ecology and Management, 245, 118-129.

Tullus, A., Rytter, L., Tullus, T., Weih, M., Tullus, H. 2012. Short-rotation forestry with hybrid aspen (Populus tremula L. $\times$ Populus tremuloides Michx.) in Northern Europe. Scandinavian Journal of Forest Research, 27, 10-29. DOI: 10.1080/02827581.20 11.628949

Yu, Q., Pulkkinen, P. 2003. Genotype-environment interaction and stability in growth of aspen hybrid clones. Forest Ecology and Management, 173, 25-35.

Žiauka, J., Kuusiene, S., Šilininkas, M. 2013. Fast growing aspens in the development of a plant micropropagation system based on plant-produced ethylene action. Biomass and Bioenergy, 53, 20-28. 